\title{
Documentos
}

\section{Espermicida y espermiostático: ¿hacen referencia a lo mismo?}

\author{
Luisa Ospina M. ${ }^{1, a}$, Walter Cardona-Maya, PhD. ${ }^{1}$ \\ ${ }^{1}$ Grupo Reproducción, Facultad de Medicina, Universidad de Antioquia. Medellín, Colombia.
}

\footnotetext{
a Microbióloga y Bioanalista.
}

\section{RESUMEN}

Antecedentes: La literatura científica ha definido los espermicidas como agentes químicos que pueden inmovilizar y algunas veces matar los espermatozoides en la vagina, sin embargo estos términos se usan de forma arbitraria y no hay un consenso que defina si la palabra espermicida debe referirse exclusivamente a una sustancia que causa la muerte espermática o a sustancias que sólo causan la inmovilización espermática y no necesariamente la muerte. Objetivo: Especificar la definición más adecuada para las sustancias que ejercen un efecto sobre la movilidad o la viabilidad espermática. Método: Revisión de la literatura en distintas bases de datos utilizando los criterios de búsqueda "espermicida" y "espermiostático", con sus equivalentes en inglés. Se seleccionaron algunos reportes en inglés y en español de los últimos 31 años, se evaluó si hacen referencia a la inhibición de la movilidad o de la viabilidad de los espermatozoides. Resultado: Se encontró que algunos reportes refieren la muerte de los espermatozoides mientras que otros sólo a su inmovilización. Conclusión: Se propone que para lograr definir si algún compuesto, extracto o sustancia con efecto sobre los espermatozoides es un agente espermiostático o espermicida es necesario que se realicen evaluaciones tanto del efecto sobre la movilidad como de la viabilidad espermática.

\section{PALABRAS CLAVE: Espermatozoide, espermicida, espermiostático, movilidad espermática, viabilidad espermática}

\section{SUMMARY}

Background: The literature has defined spermicides as chemical agents that immobilize and occasionally kill sperm cells in the vagina, however these terms are used arbitrarily and there is no consensus that defines whether the word spermicide must refer exclusively to a substance that kills sperm or substances that only cause sperm immobilization and not necessarily the cell death. Aim: To specify the most appropriate definition for substances those have an effect on sperm motility or viability. Method: We conducted a review of the literature in different databases using the search criteria "spermicide" and "espermiostátic". We selected some reports in English and Spanish for the last 31 years, and then we evaluated if they refer to the inhibition of the mobility or sperm viability. Results: We found that some reports relate the death of sperm cells while others only affect the sperm motility. Conclusion: We propose that in order to determine whether a compound or substance extract is a spermicidal or spermiostatic agent, is necessary to conduct tests of the effect on both motility and sperm viability.

KEY WORDS: Sperm, spermicide, spermiostatic, spermatic motility, spermatic viability 


\section{INTRODUCCIÓN}

Espermicida o su equivalente en inglés -spermicide- es definido como "una sustancia que inhibe la actividad de los espermatozoides, por lo cual se usa como anticonceptivo" $(1,2)$. La literatura científica ha definido los espermicidas como agentes químicos que pueden inmovilizar y algunas veces matar los espermatozoides en la vagina, inhibiendo su viaje por el tracto reproductivo femenino (3-6). Es claro que los términos matar, inhibir o inmovilizar se usan de forma arbitraria y no hay un consenso que defina si la palabra espermicida debe referirse exclusivamente a una sustancia que causa la muerte espermática o a sustancias que sólo causan la inmovilización celular y no necesariamente la muerte. El sufijo CIDA significa matador o exterminador y en el contexto biológico hace referencia a sustancias que producen muerte a organismos vivos, por ejemplo hongos -fungicida-, insectos -insecticida- o hierbas -herbicida- (7). Se ha encontrado que algunos compuestos considerados espermicidas no causan necesariamente la muerte de los espermatozoides, sólo su inmovilización $(8,9)$, lo que en realidad acuñaría el término espermiostático, sin embargo el término espermicida se utiliza comúnmente y sin distinción entre muerte o inmovilización espermática.

En la literatura científica se encuentra un importante número de reportes de sustancias y compuestos e inclusive extractos de plantas que ejercen algún efecto sobre los espermatozoides, postulados como posibles métodos anticonceptivos luego de causar la inmovilización o muerte de espermatozoides in vitro.
El objetivo de esta comunicación es concretar la definición más adecuada para las sustancias que ejercen un efecto sobre la movilidad o la viabilidad espermática.

\section{MATERIAL Y MÉTODO}

Se llevó a cabo una revisión de la literatura científica en las bases de datos PUBMED, Science Direct y en el motor de búsqueda Google Académico utilizando los criterios de búsqueda "espermicida", "espermiostático" y sus equivalentes en inglés. Se seleccionaron algunos reportes tanto en inglés como en español de los últimos 31 años. Adicionalmente se evaluó si los reportes hacen referencia a la inhibición de la movilidad o de la viabilidad de los espermatozoides, y qué uso actual tienen, para finalmente determinar qué definición podría tener cada compuesto según su mecanismo de acción.

\section{RESULTADOS}

Aquellas sustancias que tienen efecto espermicida debido a que causan la muerte de los espermatozoides mediante diferentes mecanismos de acción son las más comunes y encontradas en la literatura. En la Tabla I se encuentran los reportes de sustancias, compuestos o extractos de plantas con efecto sobre los espermatozoides considerados espermicidas, y la definición sugerida que debería tener cada uno según su efecto sobre los espermatozoides así como el uso actual que se reporta de dichas sustancias.

\section{Tabla I}

SUSTANCIAS, COMPUESTOS O EXTRACTOS DE PLANTAS, CON EFECTO SOBRE LOS ESPERMATOZOIDES: DEFINICIÓN COMO ESPERMICIDA O ESPERMIOSTÁTICO SUGERIDA Y USO ACTUAL

\begin{tabular}{|c|c|c|c|}
\hline Nombre del compuesto & Efecto sobre los espermatozoides & $\begin{array}{l}\text { Definición del com- } \\
\text { puesto según efecto }\end{array}$ & Uso actual \\
\hline Nonoxinol-9 & $\begin{array}{l}\text { Es un surfactante responsable de } \\
\text { la disolución de los lípidos de la } \\
\text { membrana del espermatozoide } \\
\text { causando su muerte }(3,10)\end{array}$ & Espermicida & $\begin{array}{l}\text { Es el agente espermi- } \\
\text { cida más común y se } \\
\text { dispone en distintas } \\
\text { presentaciones como } \\
\text { tabletas y en condo- } \\
\text { nes con } 50-150 \mathrm{mg} \\
\text { del producto }(3,11,12)\end{array}$ \\
\hline Menfegol & $\begin{array}{l}\text { Su principio activo (P-mentanil- } \\
\text { fenil-olixietileno }[8,8] \text { éter causa } \\
\text { muerte inmediata de los esper- } \\
\text { matozoides al contacto con los } \\
\text { mismos (13) }\end{array}$ & Espermicida & $\begin{array}{l}\text { Se encuentra disponi- } \\
\text { ble en el mercado con } \\
\text { distintos nombres y se } \\
\text { dispone en tabletas, } \\
\text { espumas o en condo- } \\
\text { nes impregnados con } \\
60 \mathrm{mg} \text { del producto } \\
(3,13,14)\end{array}$ \\
\hline
\end{tabular}


Continuación Tabla I

\begin{tabular}{lll}
\hline Nombre del compuesto $\quad$ Efecto sobre los espermatozoides & $\begin{array}{l}\text { Definición del com- } \\
\text { puesto según efecto }\end{array}$ & Uso actual
\end{tabular}

\section{Octoxynol}

Saponinas provenientes del extracto de Sapindus mukorossi

\section{Extractos acuosos de Pas-} siflora edulis y de Ananas comosus

Extracto de semilla de Chenopodium album

Saponinas purificadas provenientes de los extractos de Mollugo pentaphylla y de Madhuca latifolia

Jugo de Citrus lemon

Ácido acético gosipol y emulsión de aceite de semilla de algodón

Cuatro moléculas de disulfuro

Fracción polar proveniente del extracto de hojas de Sapindus saponaria $\mathrm{L}$
Disuelve los lípidos de membrana de los espermatozoides causando su muerte (3)

Detergente que disuelve los lípidos de membrana de los espermatozoides causando su muerte (3)

Promueven la formación de vesículas y vacuolas causando daño sobre la membrana espermática e induciendo la muerte celular (17)

Disminuyen de forma significativa la viabilidad espermática $(19,20)$

Promueve la lipoperoxidación de la membrana espermática, la oxidación de proteínas y la producción de radicales libres causando la muerte (21)

Causan un incremento en la lipoperoxidación y finalmente daño en la membrana plasmática $(22,23)$

Inmoviliza el $100 \%$ de los espermatozoides (24)

Inmovilizan los espermatozoides a través de la disminución del ATP intracelular (25)

Afectan de forma significativa la movilidad espermática (9)

La movilidad más no la viabilidad espermática después de 5 minutos de contacto con los espermatozoides (8)

\section{Espermicida}

Se encuentra disponible en el mercado Australiano como anticonceptivo (15)

Espermicida

En combinación con otros agentes como Nonoxinol-9 se utiliza en esponjas impregnadas con los productos (16)

Espermicida

Su uso clínico como anticonceptivo con el nombre de CONSAP se aprobó en India (18)

Espermicidas

Espermicida

Espermicidas

Espermiostático

Espermiostáticos

Espermiostáticos

Espermiostático
Productos testeados in vitro

Producto testeado in vitro

Productos testeado in vitro

Producto testeado in vitro

Producto testeado in vitro

Productos testeados in vitro

Producto testeado in vitro 
En resumen, se encontró que varios de los reportes de sustancias o extractos con efecto sobre los espermatozoides son considerados espermicidas a pesar que sólo afectan la movilidad espermática, esto podría explicarse porque desde hace varios años se define como espermicida a cualquier sustancia que pueda inmovilizar o matar los espermatozoides (4), sin embargo podría llegar a establecerse la diferencia entre las sustancias con efecto sobre la movilidad o la viabilidad de los espermatozoides. Nuestro grupo, describió cómo el agente antiviral Tenofovir afectó la movilidad espermática en humanos, aunque no la viabilidad y fue definido como un compuesto con escasa actividad espermiostática (26), no obstante es poco común que en la literatura científica se encuentre referencia a dicho término ya que pocos reportes lo destacan.

\section{CONCLUSIÓN}

Se propone que para lograr definir si algún compuesto, extracto o sustancia con efecto sobre los espermatozoides es un agente espermiostático o espermicida es necesario que se realicen evaluaciones tanto del efecto sobre la movilidad como la viabilidad espermática, y así finalmente se puede concluir según su mecanismo de acción o hallazgos experimentales, a cuál de los dos términos hace referencia ya que una sustancia que inhiba la movilidad espermática no necesariamente actúa como espermicida hasta comprobarse que afecta también la viabilidad espermática.

Agradecimiento: Estrategia de Sostenibilidad 2013-2014, Universidad de Antioquia. Ospina L., es Joven Investigadora de Colciencias.

\section{REFERENCIAS}

1. Real Academia Española. Diccionario de la Lengua Española 2012. Disponible en: http://www.rae.es/rae. html.
2. Oxford Dictionaries 2010. Disponible en: http:// oxforddictionaries.com/definition/english/ spermicide?q=spermicide.

3. Grimes D, Lopez L, Raymond E, Halpern V, Nanda K, Schulz K. Spermicide used alone for contraception (Review). The Cochrane Collaboration [Internet]. 2010.

4. Gupta G. Microbicidal spermicide or spermicidal microbicide? Europ J Contracept Reprod Health Care 2005;10:212-8.

5. Lee $\mathrm{CH}$. In vitro spermicidal tests. Contraception 1996;54:131-47.

6. Uribe-Clavijo M, Ospina L, Álvarez-Gómez A, CortésMancera F, Cadavid A, Cardona-Maya W. Espermicidas: una alternativa de anticoncepción para considerar. Tecno Lógicas 2012;28:129-45.

7. Diez Lozada F. La tribuna del Idioma. Primera Edición. Editorial Tecnológica de CR; 2004.

8. Ospina L, Álvarez-Gómez A, Arango V, Cadavid A, Cardona-Maya W. Actividad espermicida y citotóxica del extracto de Sapindus saponaria L. (jaboncillo). Rev Cub Plantas Medicinales 2013;18:187-200.

9. Florez M, Diaz ES, Brito I, Gonzalez J, Morales P. $\mathrm{N}, \mathrm{N}$-'Dithiobisphthalimide, a disulfide aromatic compound, is a potent spermicide agent in humans. Syst Biol Reprod Med 2011;57:309-17.

10. Hillier SL, Moench T, Shattock R, Black R, Reichelderfer $P$, Veronese $F$. In vitro and in vivo: the story of nonoxynol-9. J Acquir Immune Defic Syndr 2005;39:1-8.

11. Van Damme L. Clinical microbicide research: an overview. Trop Med Intern Health 2004;9:1290-6.

12. World Health Organization. WHO/CONRAD Technical Consultation on Nonoxynol-9. World Health Organization, Geneva, 9-10 October 2001: Summary Report. 2001.

13. Oshio S, Ozaki S, Ohkawa I, Tajima T, Tomomasa H, Amemiya $\mathrm{H}$, et al. Spermicidal activity of menfegolcoated condom. Andrologia 1990;22:291-6.

14. United Nations Population Fund. Frequently Purchased Contraceptives. [2013-05-02]. Disponible en: http://web.unfpa.org/procurement/commodities.htm.

15. Dawson J. Spermicidal preparations and uses thereof EP 1715874 A12006.

16. Ayotte N, Colin P. Spermicidal activity of a new contraceptive sponge. Adv Ther 2002;19:219-28. 